\title{
Design in Government
}

\author{
CATHI HO SCHAR \\ University of Hawai'i at Manoa
}

Today, governments must address the demand for solutions to complex and multi-dimensional urban and regional problems, greater citizen engagement, participatory democracy, innovative leadership practices, and organizational change. According to the Observatory for Public Sector Innovation's (OPSI) global review, "Governments and their partners are undergoing transformation to overcome unprecedented challenges and seize vast opportunities". This need for change has opened up a new space for design and innovation in government also fueled by the "growing interest in evidence-based policy making and the application of "design thinking" to policy-making". However most of this integration of design-thinking and design has focused around service and information design rather than environmental design, which forces the question: What is the role of the environmental design disciplines in this transformation? This paper explores various past and emerging models of design and government partnerships to provide a context for envisioning this future role, including a new hybrid model for university and government alignment presented by the newly established University of Hawai'i Community Design Center. Finally, this paper will end with a summary of the interactive session held at the 2019 ASCA Less Talk More Action conference that asked attendees to apply this inquiry to the design of an Office of Design within their academic or governmental institutions.

\section{INTRODUCTION}

The relationship between design and government has long been talked about relative to material expressions of power, authority, democracy or other forms of governance. This discussion departs from those ideas to focus on design as it relates to the government's provision of public goods and services, those which the marketplace cannot provide: public health and welfare programs, education, roads, national and domestic security, and clean environments. These goods are defined by their nonexcludability, meaning, noone can be excluded from their benefits. They are by definition for $100 \%$ of the public, which aligns government interest with public interest, in theory. The Latrobe Prize report, Wisdom from the Field, A Guide to Public Interest Practices in Architecture, describes public interest design as a typology of practice that has emerged "to address public needs unmet by the private market" much of it dedicated to "serving those who cannot afford the services of our profession and to address systemic problems in the built environment that create the needs in the first place." In the executive summary of this report, the question is posed, "How can Public Interest Design Practices be Sustained and Expanded?" Among the recommendations, the following was of particular interest to this discussion:

Pursue broader scale, systemic solutions. While public interest design in its various forms has shown growth over the last ten years, the overall scale of the work remains small. Several of the interviewed practitioners proposed that the challenge is to move from small, individual projects to larger scale, systemic problems...Systemic design of neighborhoods, and even cities, that includes consideration of public policies and programs, participatory processes with design decision-makers, and research, offers the opportunity for a profound transformation of the designed environment as well as a financially viable way of making a living.

In the report, which represents feedback from 383 AIA members and interviews of 100 recognized public interest practitioners, both the definition of the field of public interest design and recommendations for its future orient toward systems. Yet the report does not discuss or specifically recommend working with one of the primary administrators of systems: government. Arguably this is because public interest design emerged to address the gaps left by government, facilitating a tension between public interest and government interest. Still, the two have alignments that provide a foundation for this paper.

\section{TYPOLOGIES}

To provide context, this paper includes examples of government partnered design services and practices, most of which fall under the category of public sector design, a "growing suite of design logics, traditions, and practices that are currently being applied to matters of governance". The examples are select case studies that do not reflect a comprehensive or scholarly survey of all past or current models. The case studies suggest typologies that reflect different relationships to government, (internal, external, or hybrid) and types of services (administrative, design, advocacy, or advisory). Diagrams of these typologies are shown in Figure 1. 

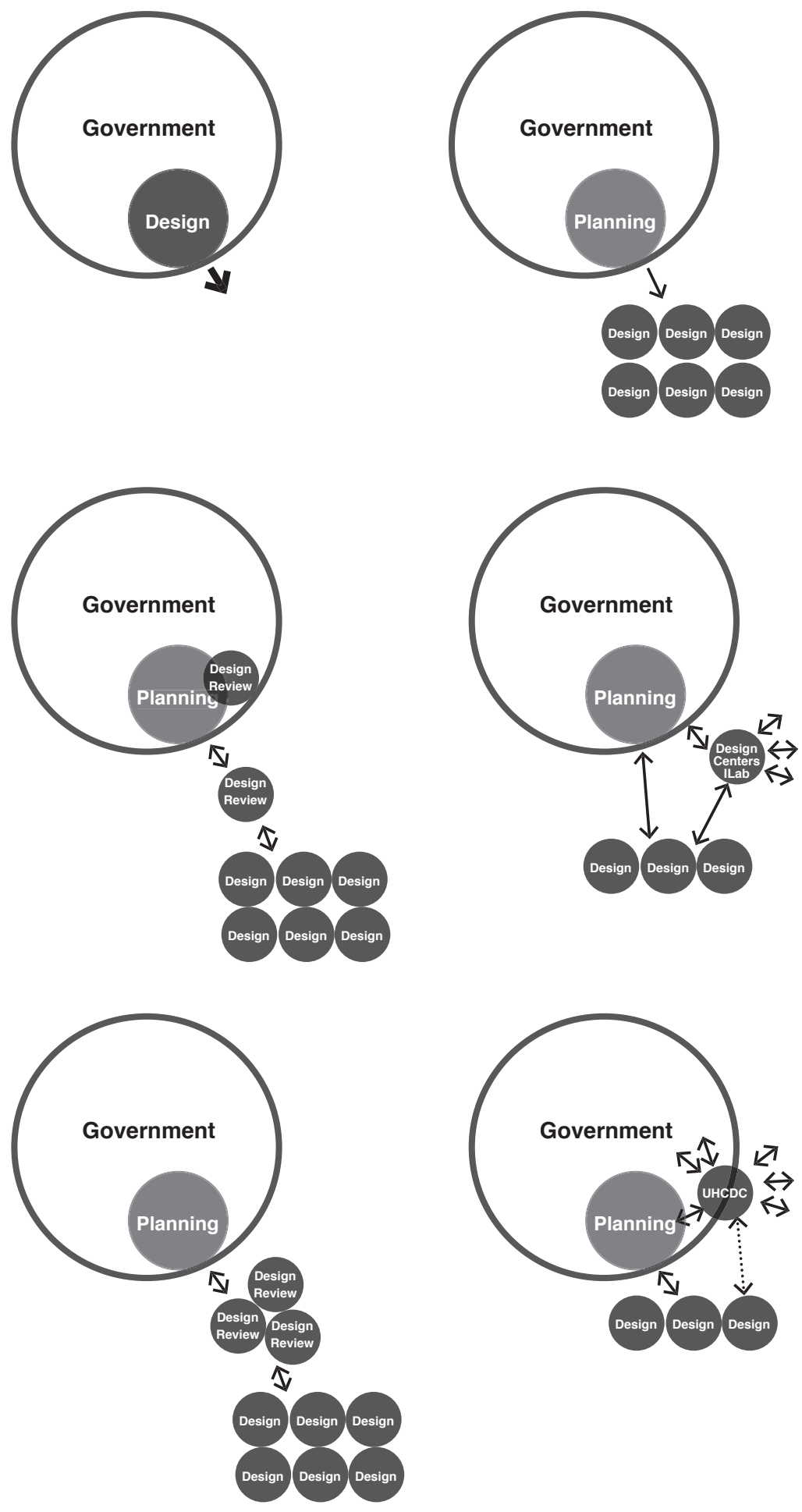


\section{INTERNAL - ADMINISTRATIVE}

Many planning and design offices in government are primarily administrative. A brief history of internal design services in the United States government is described on the Government Services administration website, starting with the Bureau of Construction. In 1852 it was established to oversee federal design and construction projects and Ammi B. Young was named the first government "Supervising Architect". Federal government buildings were designed internally by this office up until 1893, when the Tarsney Act allowed private architects to work on federal buildings, thereby transitioning the office into a more administrative and managerial role. In following years, the Office of the Supervising Architect was transferred to the Public Works Branch, and the Public Works Branch was moved to the Public Building Administration. Then in 1949, the US General Services Administration (GSA) was created to include the Public Building Services, which continues to oversee design, construction, and management of federal projects. Since the 1990s, the GSA has also worked to advocate for good design, through its GSA Design Awards, Design Excellence program, First Impression initiative, and National Awards programs. At the state level, the Office of the Architect or equivalent offices often provide services similar to the GSA. In California the Office of the Architect is responsible for design and construction oversight and development of standards and codes. In Colorado, the Office of the Architect lists similar responsibilities, but also includes coordination of the state's real estate program and capital construction budget requests. For the most part, these offices adhere to the model established by the GSA.

\section{INTERNAL - DESIGN}

More recently, there has been a proliferation of design units within governments worldwide that represent the field of public sector innovation. Public sector innovation labs typically apply design-thinking, service design, user research, ethnographics, and behavioral economics approaches to the task of improving government services. The Danish innovation unit Mindlab, was one of the first in-house public sector innovation labs to integrate user-centered design and training across governmental units. Established in 1999 Mind lab was housed in the Ministry of Industry, Business and Financial Affairs, Ministry of Employment and Ministry of Education. Other similar entities include La27eRegion in France, and the Boston Mayor's Office of New Urban Mechanics. While this trend toward design-based offices in government is fairly new, the Bloomberg American Cities Initiative 2018 American Mayor's survey reveals that $34 \%$ of the surveyed cities have dedicated staff for innovation. A leader for Bloomberg Philanthropy's Innovation Teams program that funds innovation teams in select cities, noted that 20 of the program's i-teams now include designers, which was not the case prior. This trend supports the notion that design is a critical component to innovation in government.

\section{EXTERNAL - ADVISORY}

The public sector innovation field is not limited to internal government offices, and consists of many independently run non-profit, for-profit, and government enabled enterprises that work in similar ways to the previous examples. These labs have different approaches to improving government, including design, open data, evidence-based research, or combinations of all three. Of these labs, the Design Council in the U.K. is one of the few that also provide environmental design services. The Design Council is a non-profit charity organization that describes itself as the "government's advisor on design", providing strategic advice, pre-procurement design consultation, ideas incubation, and research and insight. Their model establishes a role for environmental designers in this array of services, and space for architectural design education, organizations, and practice to embrace service, system, and policy design as supporting skillsets.

A discussion about external partnerships between designers and government should also include the role of design review boards. The City of Seattle established Design Review, where members of the public and profession consider a broad set of design considerations and apply these to projects to promote suitability to surrounding neighborhoods. This review also supports discussion on flexibility with code standards to accommodate better design. This design review differs from typical neighborhood board meeting in that it is a designdriven discussion, focused on size, shape, materials, and other visual elements. Other issues such as traffic, parking, etc., are not addressed by this process. The City of Seattle also established the People's Choice Urban Design Awards to "promote public involvement in and understanding of the Design Review Program in Seattle". These two complimentary programs represent an integrated thought involving both review and advocacy.

\section{INTERNAL - ADVOCATE}

An interesting addition to this discussion is the formation of the City of Los Angeles' Design Office, which was established in 2018 by Mayor Eric Garcetti. The office is directed by long time Los Angeles Times architectural critic Christopher Hawthorne, and tasked with elevating design in the city and establishing design as part of the city's identity. While Hawthorne is still new to the position, his work has focused on design competitions, enhanced civic engagement, and interactions with architects through informal reviews and conversations about proposed work held in their own offices. Hawthorne provides personal critique on projects, and by doing so, operates as a government-based design advocate or design champion, offering yet another role for design in government.

\section{HYBRID - DESIGN}

Finally, there are few entities that can occupy and act in a space both internal and external to government, the public university being one of them. The University of Hawaii Community Design Center (UHCDC) provides a new model for university 


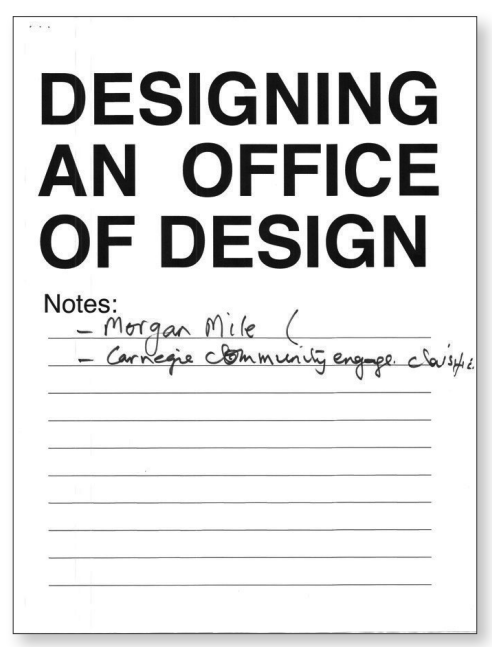

What problems will the design office work to solve:

- Community Engagement based RFP.

- Identifynie Benchmarks + glbbal Casestuden

- Zoning Revisions based on Sire Invest-

What people will it need to solve them (education/experience, \#

FTE)

Urban Planning Archilects

Land scape Archirects

Urban Desiners. Masapents.

Where does it get its authority,

how does it maneuver?

Hopeffly, City B baltemore + the Mayor's Office

$$
\overline{ }
$$

Draw and diagram indicating where your office is located within a governmental organizational structure of your own design.

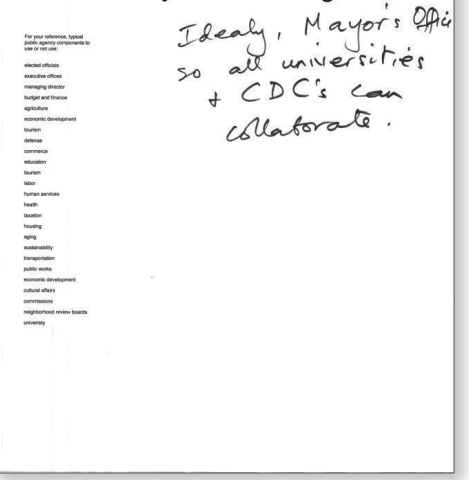

Draw the organizational structure of your city or state government. Indicate where "design" is located if at all.

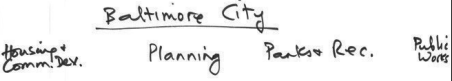
Private Sector Practices

Develop 3 programs or initiatives that the office will introduce to address its goals.

- Mobile Rink Tank

- Participatory Desin Research.

- Service Learnine CCar negie community engagement clanicfication

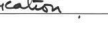

How will the office interface with design education?

$$
\begin{gathered}
\text { Through The design of measurements. } \\
\text { - Community Berefits }
\end{gathered}
$$$$
\text { - Learnine Out comes (student) }
$$

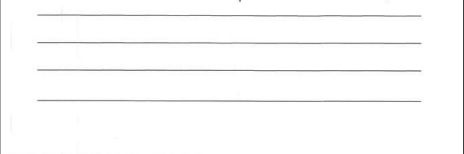

Draft a resolution to establish your office of design. 
and governmental partnership on built environment projects that embraces this unique positioning. UHCDC developed from a close collaboration between a state senator and the School of Architecture. What resulted is a state university-based community design center partnered with twelve state agencies. This led to over $\$ 2$ million in extramural applied research and design work, and provided opportunities for over 20 faculty members, 10 full time staff, 70 student interns, and hundreds of students enrolled in UHCDC project related courses. After four years of government-partnered work, the center has embraced its role as a public sector practice and as a defacto "office of design" for the state. This experience framed the questions posed to conference participants who were asked to design an office of design based on their own experience.

\section{INTERACTIVE EXERCISE}

Session participants were each given an 18 " $\times 22$ " set of worksheets that led them through a process of questions aimed at designing a speculative office of design. See Figure 2. They were asked to:

Draw the organizational structure of your city or state government. Indicate where "design" is located if at all.

What problems will the office work to solve?

What people will it need to solve them (education/ experience, \# FTE)

Where does it get its authority, how does it maneuver?

Develop 3 programs that the office will introduce to address its goals?

How will the office interface with design education?

Draw a diagram where your office will be located.

Draft a resolution to establish the office of design.

Participants suggested that these offices of design should be located at the city government level, under the Office of the Mayor. This office could partner with university entities and non-profits, and would introduce opportunity rather than competition between these groups. This was a concern from one of the participants teaching in a Baltimore university, which is surrounded by several well-established non-profit community design centers, where competition posed an issue. Participants also offered a range of problems that the office would be positioned to solve, including the development of community engaged requests for proposals (RFPs), identifying benchmarks based on global case studies, and proposing zoning revisions based on site investigations. Unfortunately due to time constraints, the group didn't get to the latter half of the worksheet questions.
What the group did spend time on, was the difficulty in institutionalizing public interest or civic practices within the university. The group discussed the Carnegie Community Engagement classification as one way of doing this. The application requires universities to submit evidence of community engaged practices in the following areas: institutional identity, culture and communication, community relations, outreach and partnerships, curricular and co-curricular engagement, professional activity and scholarship, infrastructure and finance, tracking, monitoring and assessment, faculty and staff support and rewards, and alignment with other institutional initiatives.

The group agreed that this classification offers an important catalyst for institutional change, though everyone was not aware of it.

Finally, this reflection on the conference session has to recognize the small number of participants who attended. While the small group of five offered robust and genuine conversation, the minimal attendance implies a lack of interest in new relationships between architecture and government. This questions our true commitment to more systems level action and agency within our discipline. It also highlights a potential lack of strategic communication. There was probably no session title less provocative than "Design in Government". While this was deliberately self-evident, this may not be the right strategy for architectural educators, or anyone for that matter. Moving forward, any description of this topic should consider the interests of the audience with the goal of increasing levels of participation and exchange. The emerging partnerships between designers and governments worldwide suggest that there is a new space for design that architecture is only just beginning to explore. Messaging this opportunity is critical to any progress in this direction.

\section{ENDNOTES}

1. Observatory of Public Sector Innovation. Embracing Innovation in Government Global Trends 2019

2. McGann, Michael, Emma Blomkamp, and Jenny M. Lewis. "The rise of public sector innovation labs: experiments in design thinking for policy." Policy Sciences 51, no. 3 (2018): 249-267

3. https://www.econlib.org/library/Topics/HighSchool/RolesofGovernment. html. Accessed Novermber 12, 2019

4. Feldman, Roberta, Sergio Palleroni, David Perkes, Bryan Bell. Wisdom from the Field: A Guide to Public Interest Practices in Architecture

5. Feldman, Roberta, Sergio Palleroni, David Perkes, Bryan Bell. Wisdom from the Field: A Guide to Public Interest Practices in Architecture

6. Clarke, Amanda, and Jonathan Craft. "The twin faces of public sector design." Governance 32, no. 1 (2019): 5-21.

7. https://www.gsa.gov/about-us/background-history/a-brief-history-of-gsa. Accessed November 13, 2019

8. Bloomberg Philanthropies. 2018 American Mayor's Survey 2018

9. https://www.designcouncil.org.uk/, accessed November 13, 2019

10. http://www.seattle.gov/sdci/about-us/who-we-are/design-review, accessed November 13, 2019

11. http://www.seattle.gov/sdci/about-us/who-we-are/design-review, accessed November 13, 2019

12. https://www.washington.edu/community-engagement/carnegie-classification/, accessed November 12, 2019 